\title{
What can we learn from Europe?
}

\section{K Swedberg}

Heart 2005;91(Suppl II):ii21-ii23. doi: 10.1136/hrt.2005.062059

The European Society of Cardiology has produced guidelines for the treatment of acute myocardial infarction as well as for chronic heart failure and for the use of $\beta$ blockers and angiotensin converting enzyme inhibitors. These documents provide clear evidence and strength of recommendations for the secondary prevention of complications after a myocardial infarction. The identification of heart failure and left ventricular systolic dysfunction are important risk factors in this context. The use of secondary prevention treatments in Europe has been evaluated in several surveys. The use of treatments varies across the participating countries and evidence based therapies in general are under-utilised. Various approaches have been taken to disseminate evidence based secondary prevention. Experience from the Italian BRING-UP collaboration illustrates how the use of $\beta$ blockers can be increased. Similarly, the Swedish RIKS-HIA registry of acute myocardial infarction has increased the use of secondary preventive treatments.

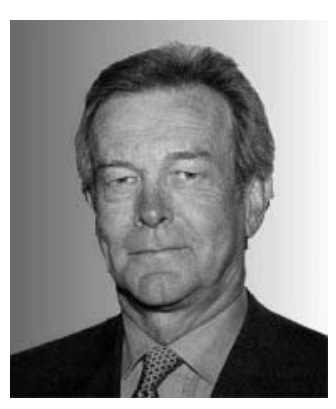

eft ventricular dysfunction, with or without heart failure, in the early phase of myocardial Linfarction (MI) is associated with increased risk of morbidity and mortality. In addition, prolonged hospitalisation (and rehospitalisation) for heart failure is common among these patients and consumes extensive resources.

To examine the incidence and consequences of heart failure complicating acute MI, Hasdai and colleagues reviewed data from 61041 patients in four thrombolysis trials. ${ }^{1}$ The presence of heart failure at admission or during hospitalisation (reported in $29.4 \%$ of patients) was shown to increase the short term risk of death or reinfarction. In the first 30 days after infarction, death and death/reinfarction occurred in $2 \%$ and $4 \%$ of patients without heart failure and in $8 \%$ and $12 \%$ of patients with heart failure. The TRACE study ${ }^{2}$ also demonstrated increased risk of mortality in patients with post-MI heart failure (defined as heart failure requiring diuretic administration or a Killip class II or more during hospital stay).

GRACE is a prospective study of patients hospitalised with acute coronary syndrome. Recent data from this registry ${ }^{3}$ on 16166 patients from 94 hospitals and 14 countries have been analysed. Thirteen per cent of patients had heart failure (Killip class II or III) on admission and this group had a fourfold increase in mortality rate during hospitalisation and increased mortality at six months compared with
Sweden:

karl.swedberg@hil.gu.se Department of Medicine,
Correspondence to: ................. patients who did not have heart failure on admission (fig 1).

The VALIANT trial showed that ejection fraction and Killip class are independently associated with prognosis in patients hospitalised with acute MI. ${ }^{4}$

\section{EUROPEAN GUIDELINES}

The European Society of Cardiology (ESC) guidelines on management of ST segment elevation $\mathrm{MI}^{5}$ recommend use of angiotensin converting enzyme (ACE) inhibitors for secondary prevention, especially in diabetic patients. The evidence to support this is level A (the strongest evidence, from at least two randomised trials), and the recommendation is class I (the strongest recommendation). There is also evidence level A, class I recommendation for use of aspirin, $\beta$ blockers (if not contraindicated), and statins (if, despite diet, total cholesterol is $>190 \mathrm{mg} / \mathrm{dl}$ ( $4.9 \mathrm{mmol} / \mathrm{l})$ and/or low density lipoprotein cholesterol is $>115 \mathrm{mg} / \mathrm{dl} \quad(2.97 \mathrm{mmol} / \mathrm{l}))$. Spironolactone is not mentioned in this document.

The recommendations on $\beta$ blockers and ACE inhibitors given in these guidelines are supported by recent ESC consensus documents on the use of $\beta$ blockers $^{6}$ and ACE inhibitors. ${ }^{7}$ It is important to emphasise that $\beta$ blockers are by far the most important pharmacological treatment for preventing sudden death in patients with LV dysfunction/heart failure.

The ESC guidelines on diagnosis and treatment of chronic heart failure ${ }^{8}$ are currently being updated but there is unlikely to be any significant change in the recommendations for use of ACE inhibitors and $\beta$ blockers. There is, however, a change regarding aldosterone antagonists. The 2001 guidelines state: "Aldosterone antagonism is recommended in advanced heart failure (NYHA III and IV) in addition to ACE inhibition to improve survival and morbidity."

Abbreviations: $A C E$, angiotensin converting enzyme; $A R B$, angiotensin II receptor blocker; BRING-UP, $\beta$ blockers in patients with congestive heart failure: guide use in clinical practice; CCU, coronary care unit; COMPANION, comparison of medical therapy, pacing and defibrillation in heart failure; CRT, cardiac resynchronisation therapy; DINAMIT, defibrillator in acute myocardial infarction trial; EPHESUS, eplerenone neurohormonal efficacy and survival study; ESC, European Society of Cardiology; GRACE, global registry of acute coronary events; ICD, implantable cardioverterdefibrillator; MADIT II, multicenter automatic defibrillator implantation trial II; MI, myocardial infarction; NYHA, New York Heart Association; RALES, randomized aldactone evaluation study; RIKS-HIA, Register of Information and Knowledge about Swedish Heart Intensive care Admissions; TRACE, trandolapril cardiac evaluation; VALIANT, valsartan in acute myocardial

infarction trial 


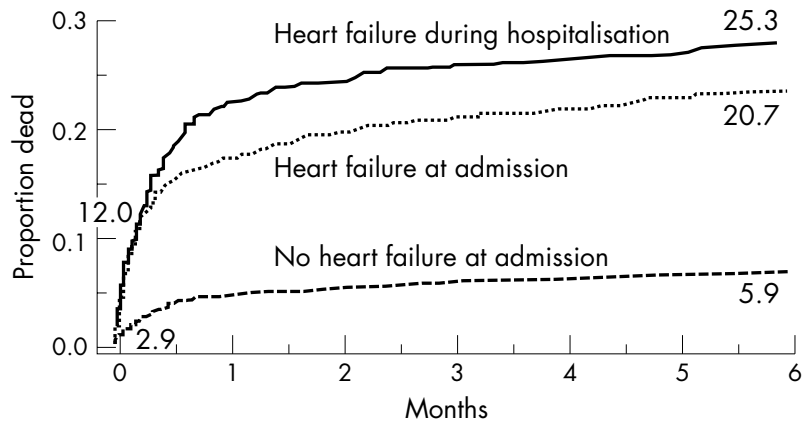

Figure 1 Data from the GRACE registry showing survival postmyocardial infarction according to presence or absence of heart failure. Adapted with permission from Steg et al. ${ }^{3}$

That recommendation was based on the results of the RALES trial. ${ }^{9}$ In that trial, only $11 \%$ of patients were taking $\beta$ blocker therapy. The draft updated guidelines will include a statement based on the results of the EPHESUS trial. ${ }^{10}$ It is at present difficult to extend the findings from EPHESUS into more advanced chronic heart failure or the experience from RALES into less symptomatic situations - that is, to bridge the findings from the EPHESUS and RALES trials to provide evidence based recommendations.

There is much uncertainty among experts as to how to interpret the evidence on the use of electrical devices. The DINAMIT trial of early post-MI management with implantable cardioverter-defibrillators (ICDs) demonstrates the complexity of the issues. In this trial (reported at the 2004 American College of Cardiology Scientific Sessions) there was no significant difference between the ICD group and the control group in all cause mortality. However, the ICD group had a highly significant ( $\mathrm{p}=0.0094)$ reduction in arrhythmic death and a significant increase $(p=0.016)$ in nonarrhythmic death. There is also the question of how to incorporate the experience from MADIT II, ${ }^{11}$ a randomised controlled trial of ICD in patients with reduced left ventricular function after MI. The selection of patients, the limited follow up (20 months), increased morbidity with ICD, and low cost effectiveness make it difficult to extend the findings into a general population with chronic heart failure.
The COMPANION trial ${ }^{12}$ included patients with left ventricular systolic dyssynchrony and chronic heart failure and provides evidence that implantation of an ICD in combination with cardiac resynchronisation therapy (CRT) (biventricular pacing) is associated with reduction in mortality and morbidity. It is not clear whether there would also be benefit from CRT alone.

\section{APPLYING THE EVIDENCE}

The Swedish coronary care unit (CCU) registry (Register of Information and Knowledge about Swedish Heart Intensive care Admissions; RIKS-HIA) is a national registry that started in 1991. At present, 74 of 78 Swedish hospitals participate, covering more than 95\% of Sweden's CCU patients. Over 60000 new patients are included each year on the online system. The register is available in English and Swedish (www.riks.hia.se).

The RIKS-HIA data suggest that there has been a decline in the proportion of acute MI patients showing clinical signs of heart failure over the past 10 years, from more than $50 \%$ in the early 1990 s to $30-35 \%$ in $2003 / 4$. However, this observation should be treated with caution: the registry has only been fully implemented for the past six years; also, there has been a change in the criteria for MI and the more recent data might include an increased number of patients with smaller infarcts. More relevant, perhaps, are the data on mortality in acute MI patients showing clinical signs of heart failure. These data indicate a trend towards a decline in inhospital mortality over the past 6-7 years.

There is evidence that the RIKS-HIA registry enhances the use of evidence based treatments. For example, in MI patients with left ventricular ejection fraction below $40 \%$, around $70-80 \%$ are currently being discharged on an ACE inhibitor or angiotensin II receptor blocker (ARB) and around $75-85 \%$ on a $\beta$ blocker, with relatively little difference between hospitals. The proportion of patients receiving the combination of ACE inhibitor (or ARB) and $\beta$ blocker is lower (around $50-70 \%$ ) and there is greater inter-hospital variation.

An analysis of data from the VALIANT trial has demonstrated significant international variation in the use of evidence based treatment in acute $\mathrm{MI}^{13}$ based on data from 14512 patients from 20 countries. Use of three key treatments-aspirin, $\beta$ blockers, and coronary reperfusion

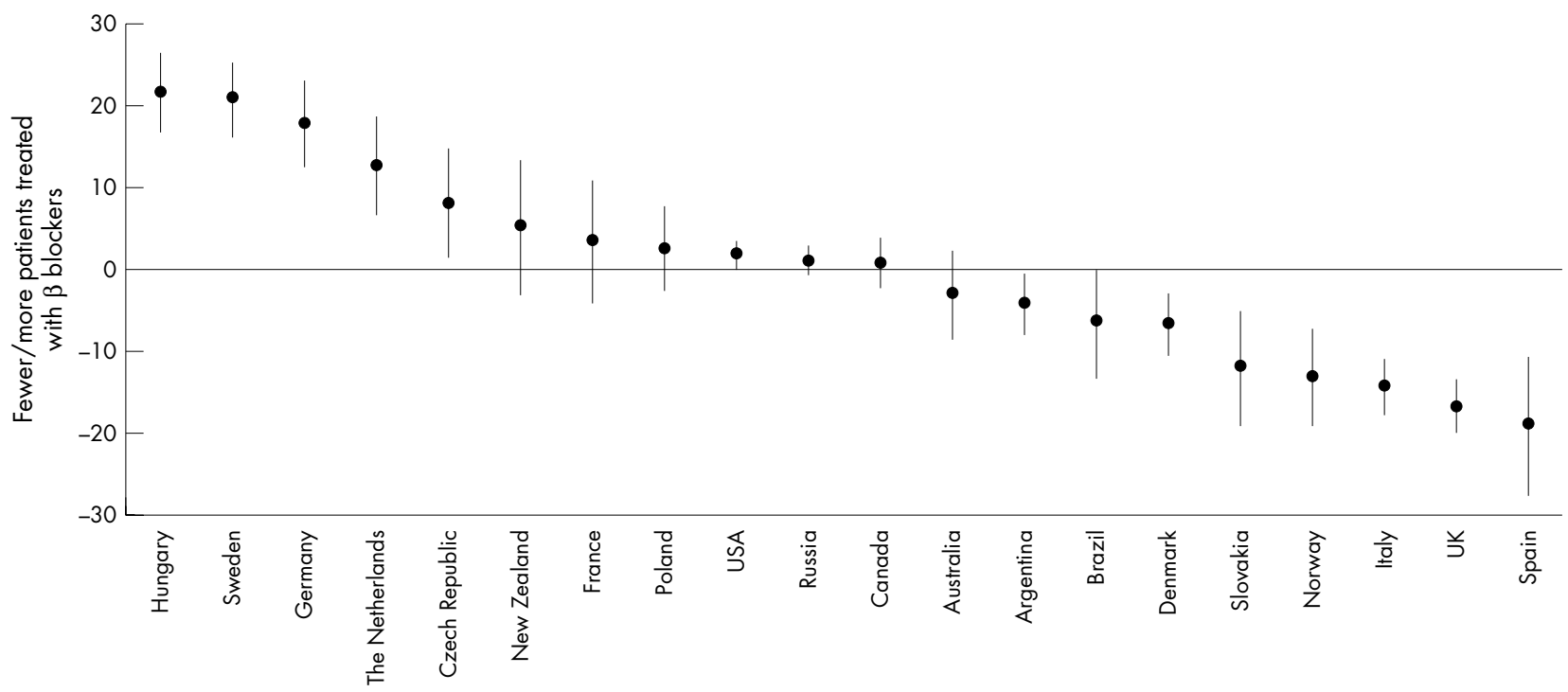

Figure 2 International variation in use of $\beta$ blockers in acute myocardial infarction, from multivariate analysis of data from the VALIANT study to compare the observed and expected rate of use of a particular treatment per 100 patients (Reed et $a^{1 / 3}$ ). 


\section{Learning points}

- Effective treatments for the secondary prevention of acute myocardial infarction (MI) are available, in particular for use in the presence of post-MI heart failure

- European Society of Cardiology guidelines provide evidence based recommendations

- European studies have shown that directed efforts can improve implementation of evidence based treatment, leading to improved quality of care

(thrombolysis or primary percutaneous coronary intervention)-was assessed. Unadjusted treatment rates, based on the case record forms, show a large variation in coronary reperfusion treatment, from $25 \%$ of patients in Russia to $75 \%$ in Germany. There was also a large international variation in the use of $\beta$ blockers. Aspirin use was high in all countries, with less variation.

Multivariate analysis allows comparison of the observed and expected rate of use of a particular treatment per 100 patients, based on the background patient demographics. For reperfusion, Germany had the highest W score (around +20) and Russia the lowest $(-16)$. This indicates that among patients with the same inclusion criteria, 36\% more patients in Germany than in Russia received reperfusion treatment. The UK score for reperfusion was second highest to that of Germany.

In VALIANT, all patients received treatment with a reninangiotensin antagonist (ACE inhibitor and/or an ARB) and so prescribing of these drugs could not be used as an index of uptake of evidence based treatment. Data on $\beta$ blockers could, however, be compared and show, for example, that $35 \%$ fewer patients in the UK than in Sweden received the beneficial effects of $\beta$ blockers post-MI (fig 2). For aspirin, the international variation was smaller.

Although these data show geographic variation in the uptake of evidence based treatments, it is important to remember that they relate only to a proportion of patientsfor example, the UK data relate to 800 patients out of the hundreds of thousands of cases of MI each year.

\section{BARRIERS TO UPTAKE OF EVIDENCE BASED TREATMENTS}

Overcoming the barriers to accepting evidence based treatments involves:

- Physician education

- Promotion of patient adherence

- Audit and feedback

- Disease management programmes

The BRING-UP Italian network demonstrates that implementation of evidence based treatment can be improved over a short time period. ${ }^{14}$ BRING-UP is a collaboration of 197 Italian cardiology centres. With the aim of accelerating the adoption of $\beta$ blockade in clinical practice, a protocol was developed on how to implement treatment in heart failure and regional meetings were held to discuss the study objective and design. All consecutive heart failure patients in a one month period were eligible for the study. Three $\beta$ blockers were provided, at appropriate doses, but the choice of whether to use a $\beta$ blocker (and at what dose) was left to the responsible clinician. The clinician was asked to give his or her reason for non-treatment. After only one year, $\beta$ blocker utilisation in these 197 centres had increased from $25 \%$ to $50 \%$, which is a remarkable achievement. The researchers comment on their strategy: "The introduction of truly innovative knowledge and behaviour into daily care is better seen as a research tool in itself." They recommend "active research projects targeted towards improving medical practice by providing a better understanding of physicians' behaviour".

\section{CONCLUSION}

Left ventricular systolic dysfunction with heart failure is common after acute MI, although the incidence may be declining. There is strong evidence for secondary preventive treatment with ACE inhibitors and $\beta$ blockers, but the use of these treatments varies widely both within countries and between countries. Improved secondary prevention requires quality measures and benchmarking by registries.

\section{REFERENCES}

1 Hasdai D, Topol EJ, Kilaru R, et al. Frequency, patient characteristics, and outcomes of mild-to-moderate heart failure complicating ST-segment elevation acute myocardial infarction: lessons from 4 international fibrinolytic therapy trials. Am Heart J 2003;145:73-9.

2 Kober L, Torp-Pedersen C, Jorgensen S, et al on behalf of the TRACE Study Group. Changes in absolute and relative importance in the prognostic value of left ventricular systolic function and congestive heart failure after acute myocardial infarction. Am J Cardiol 1998;81:1292-7.

3 Steg PG, Dabbous OH, Feldman $\sqcup$, et al for the Global Registry of Acute Coronary Events (GRACE) Investigators. Determinants and prognostic impact of heart failure complicating acute coronary syndromes: observations from the global registry of acute coronary events (GRACE). Circulation 2004; 109:494-9

4 Wilson WH, Tang EJ, Velazquez R, et al. Patterns and outcomes of revascularization in patients with heart failure and/or left ventricular systolic dysfunction following acute myocardial infarction: observations from the VALIANT registry [abstract]. J Cardiac Failure 2004;10(suppl 1):S104.

5 European Society of Cardiology. Task force on the management of acute myocardial infarction of the European Society of Cardiology. Management of acute myocardial infarction in patients presenting with ST-segment elevation. Eur Heart J 2003;24:28-66.

6 Lopez-Sendon J, Swedberg K, McMurray J, et al. Task force on beta-blockers of the European Society of Cardiology. Expert consensus document on betaadrenergic receptor blockers. Eur Heart J 2004;25:1341-62.

7 Lopez-Sendon J, Swedberg K, McMurray J, et al. Task force on ACE-inhibitors of the European Society of Cardiology. Expert consensus document on angiotensin converting enzyme inhibitors in cardiovascular disease. Eur Heart J 2004; 25: 1454-70.

8 Remme WJ, Swedberg K. Guidelines for the diagnosis and treatment of chronic heart failure. Eur Heart J 2001 ;22:1527-60.

9 Pitt B, Zannad F, Remme WJ, et al for the Randomized Aldactone Evaluation Study Investigators. The effect of spironolactone on morbidity and mortality in patients with severe heart failure. N Engl J Med 1999;341:709-17.

10 Pitt B, Remme W, Zannad F, et al for the Eplerenone Post-Acute Myocardial Infarction Heart Failure Efficacy and Survival Study Investigators. Eplerenone, a selective aldosterone blocker, in patients with left ventricular dysfunction after myocardial infarction. N Engl J Med 2003;348:1309-21.

11 Moss AJ, Zareba W, Hall WJ, et al for the Multicenter Automatic Defibrillator Implantation Trial II Investigators. Prophylactic implantation of a defibrillator in patients with myocardial infarction and reduced ejection fraction. NEng/ J Med 2002;346:877-83.

12 Bristow MR, Saxon LA, Boehmer J, et al for the Comparison of Medical Therapy, Pacing, and Defibrillation in Heart Failure (COMPANION) Investigators. Cardiac-resynchronization therapy with or without an implantable defibrillator in advanced chronic heart failure. N Engl J Med 2004;350:2140-50.

13 Reed S, Vela EJ, Swedberg K. Have international guidelines failed? International variation in the treatment of acute MI: results of the VALIANT trial. Eur Heart J 2004;25(abstract supplement):654 (abstract number 3760).

14 Maggioni AP, Sinagra G, Opasich C, et al on behalf of BRING-UP Investigators. Treatment of chronic heart failure with beta adrenergic blockade beyond controlled clinical trials: the BRING-UP experience. Heart 2003;89:299-305 